\title{
SUBJETIVIDADES INDÍGENAS: DESCOLONIZANDO HORIZONTES
}

Francis Mary Soares Correia da Rosa ${ }^{1}$

\section{RESUMO}

A proposta deste artigo é evidenciar como a literatura contemporânea de autoria indígena entendida como meio de produção promove deslocamentos e linhas de fuga na configuração de uma dada subjetividade indígena tendo como foco a obra literária de Olívio Jekupé: Kamba'i- A ajuda do Saci. O objetivo central é evidenciar como tal obra promove uma desconstrução numa dada representação hegemônica sobre a subjetividade indígena possibilitando outros sentidos, uma autodeterminação, assim como outros agenciamentos fora de uma visão canônica de literatura e mesmo, como atua no sentido de subvertê-los.

\section{PALAVRAS-CHAVES}

Literatura. Subjetividade. Indígena. Decolonialidade.

\section{INTRODUÇÃO}

"Se um leão pudesse falar, não poderíamos compreendê-lo." (Wittgenstein)

Os processos históricos que determinaram um olhar uniforme e colonial sobre a configuração dos sujeitos indígenas no Brasil como, por exemplo, a literatura indianista instituía uma visão sobre os indígenas como "elementos exóticos da terra" tendo sua imagem e representação "forjadas a partir de identidades europeias criadas por autores brancos" (MARTHA, 1999, p. 324). Tal literatura tornou-se por muito tempo uma hegemonia discursiva no que se refere à elaboração e reprodução de uma imagem sobre as diversas nações indígenas e suas especificidades.

Com o crescimento da produção literária de autoria indígena nos parece forçoso revisitar tais aspectos e compreendê-los a luz de um arcabouço teórico crítico que nos permitam elaborar aproximações destas outras formas de afeto, desejo e horizontes políticos, assim como as formações culturais e sociais que propiciaram o surgimento de diferentes subjetividades e identidades dos sujeitos indígenas marcadas pelo hibridismo cultural em um mundo onde o pressuposto globalizante tende a eliminar as diferenças culturais. Tal perspectiva busca empreender um movimento que articule ao processo de descolonização, além dos aspectos políticos e econômicos, um outro olhar, sobretudo, na própria descolonização da subjetividade e das formas de saber.

Desta forma, a proposta deste artigo é evidenciar como a literatura contemporânea de autoria indígena, entendida como meio de produção, promove deslocamentos e linhas de fuga na configuração de uma dada subjetividade indígena tendo como foco a obra literária de Olívio Jekupé: Kambai - A ajuda do Saci. O objetivo central é evidenciar como tal obra promove uma desconstrução numa dada representação hegemônica sobre a subjetividade indígena, possibilitando outros sentidos como uma autodeterminação, assim como outros agenciamentos fora de uma visão canônica de literatura e mesmo, como atua no sentido de subvertê-los.

\section{HORIZONTES NÔMADES: AS SUBJETIVIDADES EM DEVIR}

Para Frederic Jameson (2007), a continuidade histórica dos mecanismos de produção de origem capitalista, durante o século XX, deram vazão a constituição de uma lógica cultural que se relaciona diretamente, segundo o autor, as condições de reprodução e legitimação deste sistema. Segundo Jameson, ao que ele nomeia de pós-modernidade, a saber, o pressuposto histórico e cultural que fundamenta as trocas políticas e econômicas do capitalismo pós-II guerra mundial, não se restringe simplesmente a um estilo estético, mas a atuação necessária de toda uma gama de modificações no seio da própria cultura com o intuito de possibilitar o crescimento da produção de mercadorias que levaram as 1 Mestra em Critica Cultural pela Universidade Estadual da Bahia, Professora da Universidade Estadual de Feira de Santana (UEFS) e da Educação Básica, com vínculo com Secretária Estadual de Educação do estado da Bahia. 
formas capitalistas de produção ao patamar de produtoras não somente de bens materiais, mas da inserção de um certa lógica manufaturada nos modos de produção cultural, social e no âmbito das próprias subjetividades. Segundo Jameson:

\begin{abstract}
Estamos submersos no que são, a partir de agora, volumes dilatados e saturados a um ponto que nossos próprios corpos pós-modernos estão desprovidos de coordenadas espaciais, incapazes na prática (e, é claro, na teoria) de se distanciarem; ao mesmo tempo, já nos referimos a como a nova expansão do capital multinacional acaba penetrando e colonizando exatamente aqueles enclaves pré-capitalistas (a Natureza e o Inconsciente) que antes ofereciam uma base extraterritorial ou arquimediana para a efetividade crítica (JAMESON, 2007, pp. 74-75).
\end{abstract}

Tal perspectiva é um dos pressupostos fundamentais que respalda a análise do autor Peter Pal Pelbart sobre o tema da subjetividade. Mediante Pelbert (2000), a investida do capital e as variadas formas de representação da subjetividade por meio da indústria cultural evidencia que determinada visão que entendia a subjetividade como algo simplesmente referente ao modo de ser, aos afetos, ao pensamento dos sujeitos isolados e cerceados por sua própria individualidade não se sustenta mais em um mundo bombardeado intensamente por discursos voláteis e por emaranhado de multiplicidades.

A subjetividade possível, para o autor, perpassa pela rejeição de uma dada individualidade fabricada que violenta, dociliza e moraliza os sujeitos, condicionando-lhes a um estado de apatia modulável. Somente por meio da recusa de um estado de subjetividade fadado ao simulacro seria possível promover os deslocamentos dos corpos, dos afetos e dos sujeitos para um estado de devir.

Assim como destaca M. Foucault (2014), cabe imaginar outro mundo de (im)possibilidades onde a questão central seja rejeitar um individualidade sucumbida as forças de relação com o poder e investir em forças de resistência que subvertem tal ordem, que explodem em novas cartografias.

Essa relação entre individualidade e cartografias socioculturais é a própria constituição da relação entre o "fora" e o "dentro", na perspectiva de um plano da invenção de outras formas do ser, atravessado por acontecimentos e intensidades. Para Suely Rolnik,

o que observamos agora é que dentro e fora não são meros espaços, separados por uma pele com-
pacta que delineia um perfil de uma vez por todas. Percebemos que eles são indissociáveis e, pa-
radoxalmente, inconciliáveis: o dentro detém o fora e o fora desmancha o dentro. Vejamos como:
o dentro é uma desintensificação do movimento das forças do fora, cristalizadas temporariamente
num determinado diagrama que ganha corpo numa figura com seu microcosmo; o fora é uma
permanente agitação e forças que acaba desfazendo a dobra e seu dentro, diluindo a figura atual da
subjetividade até que outra se perfile (ROLNIK, 2000, p. 27).

Não se trata de insistir em uma busca de equilíbrios ou estabilidade entre as forças do fora e de dentro, mas na prática em potencial de afirmação de devires que segundo a autora, tornam a existência um campo vibrátil e potencializador da vida. ((ROLNIK, 2000, p. 27). O fora é o instante sobre o qual uma dada subjetividade cristalizada, identitária se desestabiliza e põe-se em movimento. E na tarefa de reinventar-se, de acordo Rolnik, o artista destaca-se no fluxo de produções de "microuniversos culturais" e na criação destas outras paisagens também produz outro perfil cultural: são subjetividades entrelaçadas à malha cultural, propondo curvaturas, dobras no processo de subjetivação. Para Guattari, a "subjetividade, de fato, é plural, polifônica. E ela não conhece nenhuma instância dominante de determinação que guie as outras instâncias segundo uma causalidade unívoca” (GUATTARI, 2012, p. 11).

É neste aspecto que a produção autoral de um escritor irrompe em um terreno de possibilidades e devir em que a literatura pode tornar-se propulsora de novos sentidos e de agenciamentos. Diante disto, a literatura pós-colonial, mais precisamente no caso deste artigo a literatura pós-indianista é um dispositivo agenciador de subjetividades destes povos originários que surge como uma possibilidade de por em movimento vozes silenciadas por meio da valorização e estabelecimento de um discurso ocidentalizador e lusocêntrico. 
Em Diálogos, Deleuze (1998) explana que o universo literário, tal como a arte, por muito tempo se constituiu como um decalque do modelo de representação do pensamento: os estilos, normas, escolas só funcionavam como maneiras de neutralizar devires e linhas de fuga. Contudo, há determinadas literaturas que produzem rupturas, linhas de fuga, que estão ávidas por experimentação. Desta forma, a literatura é rizomática, produz multiplicidades, provoca algum efeito, se conecta para usos, adquire funções, movimentando-se no seu devir, é uma toca, cheia de entradas. Seus personagens são sempre imagens de desterritorialização, desfazendo significações.

\begin{abstract}
Ao longo de uma grande história, o Estado foi o modelo do livro e do pensamento: o logos, o filósofo-rei, a transcendência da Idéia (sic), a interioridade do conceito, a república dos espíritos, o tribunal da razão, os funcionários do pensamento, o homem legislador e sujeito. É pretensão do Estado ser imagem interiorizada de uma ordem do mundo e enraizar o homem. Mas a relação de uma máquina de guerra com o fora não é um outro "modelo", é um agenciamento que torna o próprio pensamento nômade, que torna o livro uma peça para todas as máquinas móveis, uma haste para um rizoma (DELEUZE, 2009, p. 36).
\end{abstract}

Percebe-se que a literatura pode efetuar linhas de fuga e promover novos devires também no campo político e social, desde a reprodução de um estado de coisas até a recriação da subjetividade. O texto literário absorve e é absorvido, representa e é representado, ele é território (sedentário) e linha de fuga (nômade). Na liberdade de tudo dizer, o texto literário ultrapassa estratos cronológicos e geográficos e, faz rizomas... Florescendo no meio.

\title{
LITERATURA COMO MEIO DE PRODUÇÃO
}

Para Williams (2011), a literatura se constitui como um mecanismo produtor de saber e influência direta ou indiretamente a formação da consciência dos indivíduos, atuando como uma possível mediadora entre as interfaces das relações sociais de produção e a própria subjetivação do sujeito. Como produção artística que constrói um mundo sígnico, a literatura evoca estranhamentos e encontros tornando-se um tipo de agenciamento "maquínico" (GUATTARI, 2012) que ultrapassa velhas categorias de conhecimentos que defendem uma relação determinante na esfera de sua construção com os outros meios de produção mais gerais.

A literatura como experimentação e como meio de produção possibilita a criação de um mundo e de uma realidade própria, mediante Levy (2011), capaz de fundar uma outra dinâmica relacional entre as palavras e as coisas que vai além da relação entre significado e significante, possibilitando ao leitor uma experiência de perspectivismo onde a vivência desta outridade age como o próprio exercício e passagem para o próprio vazio da representação:

Na versão literária, por sua vez, a linguagem deixa de ser um instrumento, um meio, e as palavras não são mais entidades vazias se referindo ao mundo exterior. Aqui, a linguagem não parte do mundo, mas constitui seu próprio universo, cria sua própria realidade. É justamente em seu uso literário que a linguagem revela sua essência: o poder de criar, de fundar um mundo (LEVY, 2011, p. 20).

Assim, a literatura é um agenciamento com potencial de conectividade com outros agenciamentos, se associando a linhas de fuga, rompendo com uma lógica cristalizada entre o real e sua representação, instalando desterritorializações. Ao instaurar linhas de fuga, a escrita literária possibilita rupturas no esquema canônico e promove frestas no discurso do poder.

Em um texto intitulado "A literatura e a vida", Deleuze afirma que a literatura está em intima relação com aquilo que está inacabado, como o que estar por vir. Segundo o autor, não há componente de fuga e de devir-potência naquilo que é preponderante, que é dominante. Segundo Deleuze:

O devir não vai noutro sentido: não devimos Homem, mesmo que o homem se apresente como uma forma de expressão dominante que pretenda impor-se a toda a matéria; ao passo que mulher, animal ou molécula têm uma componente de fuga que se descarta à sua própria formalização (DELEUZE, 2011, p. 11). 
Neste sentido, a tarefa da literatura de autoria nativa contemporânea não é de compor um caminho em busca de se afiliar ao cânone ou de se tornar parte dele, se adequando até ceifar sua diferença em um jogo de “mais do mesmo". É compor uma máquina de guerra, transformando-se em um meio de comunicação capaz de desestabilizar territórios e levar seu processo de desterritorialização ao infinito.

\section{CARTOGRAFIAS DA EXISTÊNCIA: DEVIR INDÍGENA}

Em Cartografia Sentimental, Suely Rolnik nos oferece pistas de como atua o cartógrafo e quais os seus princípios. A autora nos convida a pensar em termos de desejo e de imanência de vida. Para ela, a prática de atuação de um cartógrafo está relacionada "às estratégias de formação do desejo no campo social". Interessa ao cartógrafo a metamorfose da vida, a expansão do desejo, o acontecimento e, não a solidez da estrutura.

O que define, portanto, o perfil do cartógrafo é exclusivamente um tipo de sensibilidade, que ele se propõe fazer prevalecer, na medida do possível, em seu trabalho. (...) O que ele quer é se colocar, sempre que possível, na adjacência das mutações das cartografias, posição que lhe permite acolher o caráter finito ilimitado do processo de produção de realidade que é o desejo (ROLNIK, 2006, pp. 66-67).

O cartógrafo deve estar atento aos mecanismos que procuram limitar a fluidez do mapa que nos impele a criar decalques, pois, somente ao permitir a elasticidade de seus critérios, ele estará apto a permitir a expansão da vida. Não há normas pré-fixadas a serem seguidas, mas apenas valorização da criatividade e continuidade da vida ou mesmo dos devires... Das saídas.

É por meio da atividade cartográfica que se intenta uma aproximação com uma espécie de devir-indígena, onde uma dada representação da identidade/subjetividade indígena, até então sacramentada no imaginário literário e na produção historiográfica, é recusada pela literatura de autoria dos povos originários na contemporaneidade, posto que:

quando uma personagem deixa de se manter dentro do espírito, é o próprio espírito que deixa também de se manter. É inevitável: quando uma personagem se revela "outra" do que fora até então, isso funciona como uma linha de fuga que esgarça toda a trama do enredo. A trama, neste caso, perde toda a força de encantamento que, até aquele instante, a tornava real (ROLNIK, 2006, p. 98).

Percebe-se que essa criação de outra subjetividade presente nos textos de autoria indígena nos propõem um olhar que subverte e desloca a imagem reservada aos indígenas na literatura canônica. Para Daniel Munduruku a imagem de "selvagem" e de incapaz atribuída aos grupos indígenas diz respeito justamente a uma construção etnocêntrica e unilateral da alteridade e esta mediação é balizada em uma visão de mundo que toma como unicamente válidos os seus próprios pressupostos, relegando aos indígenas uma imagem do outro, destituído de história, de escrita, estático em um passado em que foi adicionado mediante sua relação com o colonizador. (MUNDURUKU, 2009, pp. 20-24).

Ao observarmos a escrita nativa de autores como Daniel Munduruku, Olívio Jekupé, Graça Graúna, entre outros, constatamos o depositório de memórias, tradições orais e escritas, práticas de cotidiano e etc. que criam outros meios de subjetivação. Essa escrita, já presente nas tradições e pertenças culturais dos povos nativos mas, ironicamente tomada como novidade por nossa tradição lusocêntrica é um processo de territoralização, entendido na perspectiva Deleuze e Guattari (1997), onde a literatura se constitui como principal constructo simbólico e modelo de representação identitária sendo mobilizada como maquinário de resistência e deslocamento subalterno produzindo subjetividades.

Tal percepção nos coloca diante de um fazer literário que combina ao mesmo tempo uma especificidade política e étnica que se relaciona diretamente a sua condição de pronunciar uma tradição, uma voz coletiva que vai além das simples identidades enquanto indivíduos. 
Os escritores indígenas mobilizam em seus textos as tradições orais, o caráter performático de tais tradições e incorporam a etnicidade de sua nação indígena de pertencimento ao "traduzir" para a escrita uma voz coletiva, recuperando-a e experiênciando-a em um pronunciamento político que diz respeito a um povo inteiro, sua sensibilidade e sua história. Por meio desta ramificação do individual no plano coletivo os escritores nativos, através de sua menoridade literária, pronunciam um agenciamento coletivo de enunciação, em que a aparente subjetividade isolada do escritor transporta o devir revolucionário politizado do desejo de várias vozes.

Essa percepção de deslocamento e fuga em meio a um processo de movimentação política da língua, a saber, o português do não-índio sendo operado pelos grupos indígenas como no caso da obra analisada, potencializa a literatura de autoria nativa como fortalecedora dos grupos étnicos envolvidos e produtora de outros devires, nos quais a:

\begin{abstract}
emergência da literatura pós-colonial acontece pela negação e anulação dos ditames normativos eurocêntricos de padronização universal que pregam a linguagem da metrópole como norma e marginalizam as variantes como 'impuras', surgindo a ab-rogação. Esta escrita se desenvolve com a apropriação da linguagem e da escrita dominante com vistas a novos e específicos usos, pois se a língua tem condições de perpetuar a estrutura hierárquica do poder também as tem para subverter o discurso opressor e deixar emergir a eficácia da voz pós-colonial. Desta forma, a língua inglesa usada na Guiana jamais será e nem pretende ser como o 'inglês da rainha', usado na Inglaterra, e o mesmo processo acontece entre a língua portuguesa do Brasil e de Portugal (BARZOTTO, 2012, p. 84).
\end{abstract}

Para Almeida (2009), somente por meio da descolonização das subjetividades indígenas se pode engendrar a transformação dos sujeitos presentes entre as nações originárias. Não se trata somente da apropriação da escrita nos moldes ocidentais, mas, sobretudo, um deslocamento ao nível semiótico. De acordo com o autor:

livros que começam com a voz. Os povos indígenas querem ouvir a própria voz. A escrita, grande aliada das classes dominantes, paradoxalmente, torna-se a oportunidade de reversão para os dominados. Eivada das diferentes falas silenciadas, funciona como uma arma que, através de cada frase ou palavra desacostumada, detona com um certo poder: a língua enquanto instituição. É por isso que devemos inscrever os livros escritos pelos índios no campo da política (ALMEIDA, 2009, p. 90).

É, neste sentido, que a experiência da palavra escrita nas nações indígenas caminha lado a lado com uma busca por empoderamento, por um direito a uma identidade étnica e a vivência desta diferença. Percebe-se o desejo de constituir, ou melhor, de gritar a própria história. E é exatamente este o espirito geral de uma literatura de autoria indígena: engajar a própria voz, deslocar a representação da imagem de uma miríade de povos em um mundo colonizado. Essa apropriação/deslocamento do universo gráfico quiçá semiótico do mundo ocidental pela palavra escrita indígena é a rememoração das ruinas, dos resíduos, desvios e o estabelecimento de novas possibilidades de trocas linguísticas, antropológicas e culturais.

\title{
AJUDA DO SACI: BREVES MAPAS EM TRANSE
}

Indígena da tribo guarani, Olívio Jekupé estudou filosofia na USP e apesar de não ter concluído, se constituiu como um dos mais importantes nomes da literatura nativa no Brasil. Sua preocupação com o empoderamento dos grupos indígenas é notória, principalmente no que se refere à literatura de autoria nativa, postulando que é preciso que os grupos indígenas tomem a autoria de sua própria história. Segundo Jekupé:

faz tantos séculos que o Brasil foi dominado pelos jurua kuery, não índios em guarani, e desde aquela época tudo o que se fala sobre nossos parentes é escrito por eles. Eu não via isso como algo interessante, porque nós temos que contar nossas histórias para nossos filhos e se tiver que ser escrita, por que não pelo próprio índio? (JEKUPÉ, 2009, p. 11). 
Em Kamba’i - Ajuda do Saci, Olívio Jekupé constrói em seu texto um percurso de autoafirmação e empoderamento com uma obra bilíngue (português e guarani) onde a personagem central de nome "Vera" sonha em estudar na "cidade grande" e aprender a ler e escrever na língua portuguesa. Com a ajuda de um casal de não-índios, Vera concretiza o seu sonho e se destaca na classe como um dos melhores alunos, intercalando períodos na aldeia e na cidade grande até que um acidente lhe coloca em estado de coma e mais tarde imobilizado. Sem resposta positiva dos médicos, Vera volta para a aldeia onde seu pai pede ajuda ao Saci e este, personificado na figura de um pequeno índio com cachimbo, prontamente lhe ajuda, aparecendo para seu filho. Vera, ao ver o lendário Saci, levanta em sua direção e percebe que o tempo todo podia andar, apenas tinha medo de andar outra vez.

$\mathrm{Na}$ obra mencionada, podemos destacar duas personagens centrais que nos servirão de base par articular uma construção do pensamento indígena sobre sí mesmo e um exercício de empoderamento, a saber, respectivamente o garoto Vera e a figura ancestral e mística do Saci (kamba’i no idioma guarani).

A personagem de Vera configura-se como um representante da relação de alteridade presente em toda obra de Jekupé, onde há predominância de uma relação intercultural entre os encontros/desencontros com a tradição cultural com os não-índios. Uma das justificativas, presentes na obra, para que se fundamente a ida de Vera para a "cidade-grande" é a importância que existe em conhecer a cultura dos não-índios e, neste aspecto instituir a possibilidade de uma relação dialógica em contraponto ao imaginário que recupera e reproduz um eterno estado de choque irreconciliável entre culturas tão diferentes. Segundo Graúna (2013), a relação de alteridade ganha destaque na obra de Jekupé, ao propor um reposicionamento sobre o direito à diferença, além de salientar a importância do outro na construção de sua própria identidade.

A diferença entre as culturas não é destacada como um embate ou uma forçosa aculturação: o desejo do indiozinho é aprender a ler e escrever na língua portuguesa para ajudar seu povo. Logo ao chegar na escola, Verá nota que os alunos não índios percebiam sua diferença, porém a diferença não era uma veículo para discriminação, mas a oportunidade de um diálogo intercultural:

Seus amigos não indígenas ficavam impressionados com sua inteligência e ao verem que ele, além de falar guarani, falava também português. Vera ensinava aos colegas as palavras que queriam saber em guarani (JEKUPÉ, 2009, p. 17).

Percebe-se no desejo de Verá em aprender o idioma português o quanto a escrita literária indígena é, também, um exercício de cidadania, pronuncia mapas políticos e se configura como um discurso autopoiético. O vai e vem de Vera da cidade para aldeia nos fim de semana e nas férias pode ser experienciado como um movimento dialético entre alteridade e identidade, mas também dialógico onde a diferença é percebida sem caminhar para um processo de homogeneização cultural ou um encontro que busque promover identidades uníssonas.

Os kunumi correram todos ao seu encontro para saber coisas da cidade. Vera sentou-se com eles embaixo de uma árvore e falou sobre os costumes dos meninos da cidade. Contou que passam muito tempo sentados em frente a aparelhos, assistindo a programas de televisão ou jogando videogames (JEKUPÉ, 2009, p. 13)

A grande reviravolta da trama ocorre com o acidente de Vera, que sofre um atropelamento (o não índio que o atropela estava bêbado e não presta socorro) deixando a personagem imobilizada. Observa-se na personagem do motorista bêbado o tom de denúncia que remete ao local de despejo e desconhecimento com o qual as sociedades indígenas são e foram tratadas por muito tempo. Neste aspecto devemos destacar que uma literatura de autoria indígena também pode ser uma literatura menor e, como tal pode engendrar um processo de desterritorialização em que o encontro não vem com certa passividade, mas se expressa por meio de violência e explode em heterogeneidades. 
A narrativa então assume caráter afirmativo pois, após o acidente, Vera é levado de volta a tribo e ajudado pelo Saci, personagem mítico da cultura guarani, diverso da construção popularizada por Monteiro Lobato, que termina sendo responsável por ajudar o indiozinho a andar. A imagem do Saci nos remete a um elemento de autonomia, de agenciamento coletivo que impregna a obra de um caráter menor, uma relação de empoderamento para a cultura guarani que é capaz de se autodeterminar. Ao acreditar no Kamba’i a personagem de Verá volta a andar.

O Kamba'i como o Saci é conhecido em guarani é retratado na obra de forma a assegurar que é a visão guarani do mito que prevalece na tradição oral e textual indígena. Segundo Graça Graúna, o Saci é um "protetor dos homens e das matas, ou como personagem que se identifica com quem se vê ou se sente diferente, ou até mesmo deslocado dentro ou fora da aldeia. Na sua alteridade, o Saci indígena não usa gorro. Têm as duas pernas e carrega no pescoço um colar, ou baêta" (GRAÚNA, 2013, p. 156). É na apropriação que o autor faz da personagem do Saci que Jekupé demonstra o projeto de autodeterminação, o desejo de escrever a própria história e torna-se representante de uma tradição ao revitalizar no conto as tradições orais da sua comunidade guarani. Acreditar no Kamba’i tal como presente na representação guarani é também uma forma de sinalizar uma disputa identitária, descontruído estereótipos (GRAÚNA, 2013).

A personagem de Verá, uma criança - o que nos levar a pensar se não seria uma metáfora sobre o modelo de cidadania instituído no Brasil aos povos originários, onde a cidadania tutelada ainda persiste, lhes configurando um trato infantil - por meio de sua postura engajada e curiosa aprende o idioma português, o ensina aos demais da aldeia, tem sua vida ameaçada, mas, contudo, resiste e sobrevive por meio da crença na tradição e na presença do elemento ancestral. Configura-se, desta forma, uma autopoiese por meio desta obra que ultrapassa uma visão colonizada ou colonizadora, sugerindo um posicionamento político e um lugar particularizado ao criar sua própria subjetividade. De acordo com Arias:

El posicionamiento de la particularidad de la subjetividad indígena nos permite así negociar y construir modelos interculturales en base a perspectivas indígenas propias. Las literaturas indígenas introducen nuevos desafíos lingüísticos y representacionales en el proceso discursivo y simbólico (ARIAS, 2012, p. 9).

Dessa forma, se estabelece a constituição de uma nova subjetividade que é atravessada pelo elemento intercultural e hibrido. O sujeito indígena contemporâneo não apenas se movimenta na cultura majoritária como se desloca e se apropria de seus elementos constitutivos. Tal perspectiva desmonta não só o modelo de cidadania brasileiro que é pautado pela noção unívoca de razão nacional, como também permite instaurar um revisionismo nos pressupostos tidos como universais. Como destaca Viveiros (2002), recusar uma condição de ocidental que nos impede de perceber que cada sociedade postula e busca soluções para seus próprios problemas é um passo fundamental para compreender a falibilidade de um ideal de humanidade, universal e centralizado em seu próprio anthropos que nos impede de se aproximar de uma relação de alteridade com os outros humanos (e os animais também) em toda sua diferença.

\section{CONCLUSÃO: DESCOLONIZANDO SUBJETIVIDADES}

O avanço da literatura de autoria indígena produz uma variação não só na riqueza dos estilos da escrita como também promove mudanças de perspectivas estéticas, políticas e ética. Neste contexto, a experiência literária é engajada no projeto de levar a língua ao seu limite, ao seu "ponto de suspensão" (Deleuze, 2011, p. 75), tornando-se espaço para a reinvenção dos espaços sociais, culturais e a promoção de outras formas de existência, descolonizando também a subjetividade indígena. Segundo Levy: 
Nesse sentido, a experiência literária é combativa, resistente, uma vez que se coloca na contramão do que está estigmatizado enquanto verdade, da moral vigente em cada época. Pensar é antes de tudo resistir, não deixar que os valores se fixem onde estão, tornar as coisas móveis, desterritorializá-las, operar o movimento próprio do nômade (LEVY, 2011, p. 129).

Diante disto, com o avanço de autores como Jekupé há a reivindicação e a luta pela conquista de espaço para outros atores sociais, assim como a proliferação de outros jogos de linguagem. Por meio de obras como à analisada neste artigo podemos vislumbrar que o jogo micropolítico e a instância dos afetos (e de ser afetado) constitui o próprio projeto descolonizador, em que a atitude ética na literatura e na própria vida é promover a desconstrução/produção de sua própria existência. O contradiscurso oferecido pela literatura indígena é uma forma de nos aproximar e de evidenciar às diferenças presentes naquilo que tradicionalmente entendemos como literatura, assim como questionar uma visão essencialista do termo. Aliado a este aspecto, ao pôr em destaque um estudo sobre a presença indígena na produção literária e estética brasileira, esperamos possibilitar um pensamento crítico referenciado na crítica cultural e no pensamento pós-crítico que se volta para as formas como esses autores e sujeitos históricos marginalizados, oriundos de grupos historicamente subalternizados não se anularam frente às várias violências sofridas. Pelo contrário, incorporaram novas práticas sociais, culturais e políticas, em processos de etnogêneses diversos, resistindo e (re)criando à própria vida, suas identidades e suas histórias.

Apesar das variadas formas de violência sofridas, assim como o discurso etnocêntrico que promove à invisibilidade e o não reconhecimento das diversidades dos povos nativos brasileiros, às organizações indígenas se fortalecem cada vez mais e buscam descontruir o preconceito e o discurso da extinção que apregoa aos indígenas a imagem de "seres" do passado, que não dialogam com quaisquer futuros.

É o ecoar de uma voz fugidia, posta em devir-indígena, que não atende mais pela visão idílica do indígena, que no lugar do "eu" e do "tu" desloca sua escrita para o "nós" diante das normas e do cânone estabelecido (DELEUZE, 2011, p. 13), nos convidando a construção de um diálogo com outras formas de saber e de experienciar a vida, potencializando fluxos e devires não somente no campo literário, mas no próprio discurso cientifico e em um projeto universalista de humanidade.

\title{
NATIVE SUBJECTIVITIES: DECOLONIZING HORIZONS
}

\begin{abstract}
The purpose of this article is to show how the contemporary literature of indigenous authorship understood as a means of promoting production shifts and drain lines in the configuration of a given indigenous subjectivity focusing on the literary work of Oliver Jekupé: Kamba'i- Help the Saci. The main objective is to show how this work promotes deconstruction in a certain hegemonic representation of the indigenous subjectivity allowing other senses, self-determination, as well as other assemblages out of a canonical view of literature and even as acts to subvert them.
\end{abstract}

\section{KEYWORDS}

Literature. Subjectivity. Indigenous. Decolonization.

\section{REFERÊNCIAS}

ALMEIDA, M. I. Desocidentada: experiência literária em terra indígena. Belo Horizonte: Editora UFMG. 2009. ARIAS, A. Literaturas de Abya Yala1: Austin, TX : Escalante. LASA Forum, v. XLIII, Issue \#1, February 2012. CASTRO, E. V. A inconstância da alma selvagem e outros ensaios de Antropologia. São Paulo: Cosac \& Naify, 2002.

DELEUZE, G. Crítica e clínica. São Paulo: Ed. 34, 2011.

DELEUZE, G. \& PARNET, C. Diálogos. Tradução Eloisa Araújo Ribeiro. São Paulo: Escuta: 1998. 
FOUCAULT, M. O sujeito e o poder. Genealogia da ética, subjetividade e sexualidade. Col. Ditos e escritos. v. IX. Rio de Janeiro: Forense Universitária, 2014.

GRAÚNA, G. Contrapontos da literatura indígena contemporânea no Brasil, Belo Horizonte: Mazza Ediçoes, 2013.

JEKUPÉ, O. Literatura escrita pelos povos indígenas: São Paulo: Scortecci, 2009.

JEKUPÉ, O. Ajuda do Saci: São Paulo: DCL, 2006.

LEVY, T. S. A experiência do fora. Blanchot, Foucault, Deleuze. Rio de Janeiro: Relume Dumará, 2011.

MARTHA, A. A. P. Autoria indígena na produção infanto juvenil contemporânea. Maringá (PR): UEM, s/d. Disponível em http://goo.gl/MVgggj. Acesso em: 13/09/2013.

MUNDURUKU, D. O Banquete dos deuses: conversa sobre a origem da cultura brasileira. 2. ed., São Paulo: Global, 2009.

ROLNIK, S. "Uma insólita viagem à subjetividade: fronteiras com a ética e a cultura". In: LINS, D. (Org.). Cultura e subjetividade. 2. Ed., São Paulo: Papirus, 2000, pp. 25-34.

ROLNIK, S. Cartografia sentimental. Porto Alegre (RS): Editora UFRGS, 2006.

PELBART, P. P. A vertigem por um fio: políticas da subjetividade contemporânea. São Paulo: Fapesp/lluminuras, 2000.

WILLIAMS, R. Meios de comunicação como meios de produção. In: Cultura e materialismo. São Paulo: Ed. UNESP, 2011, pp. 74-79.

WITTGENSTEIN, L. Investigações filosóficas. Tradução: José Carlos Bruni. São Paulo: Editora Nova Cultural, 1999.

SUCHANEK. M. G. Povos indígenas no brasil: de escravos à tutelados. Uma difícil reconquista da liberdade. Confluências, Vol. 12, n. 1. Niterói: PPGSD-UFF, outubro de 2012, pp. 240-274.

Data de recebimento: $15 / 12 / 2015$

Data de aceite: 20/02/2016 